\title{
Poor prognostic significance of unamplified chromosome 17 polysomy in invasive breast carcinoma
}

\author{
Uma Krishnamurti ${ }^{1}$, Jennifer L Hammers ${ }^{2}$, Folefac D Atem ${ }^{3}$, Patrick D Storto ${ }^{1}$ \\ and Jan F Silverman ${ }^{1,2}$ \\ ${ }^{1}$ Department of Pathology, Western Pennsylvania Hospital, Pittsburgh, PA, USA; ${ }^{2}$ Allegheny General \\ Hospital, Pittsburgh, PA, USA and ${ }^{3}$ Department of Biostatistics, University of Pittsburgh, Pittsburgh, PA, USA
}

\begin{abstract}
The human epidermal growth factor receptor 2 (HER2) oncoprotein is overexpressed in about $20 \%$ of breast cancers, with HER2 gene amplification responsible for protein overexpression in the vast majority of patients. A subset of breast cancers have chromosome 17 aneusomy, due to either 17 monosomy (a single copy of chromosome 17) or polysomy (increased copy numbers of chromosome 17). Although HER2 overexpression is an established adverse prognostic factor in breast cancer, the role of unamplified chromosome 17 polysomy is uncertain and there is a paucity of literature on the correlation of chromosome 17 aneusomy with important prognostic and predictive pathologic factors in invasive breast carcinoma. Furthermore, while patients showing HER2 amplification with or without polysomy 17 are treated with trastuzumab with or without other chemotherapy, treatment of patients with unamplified chromosome 17 polysomy is not well defined. Currently most of these patients are treated similar to patients with neither amplification nor 17 polysomy. The aim of this study was to compare some prognostic and predictive factors in invasive breast carcinoma in patients with unamplified chromosome 17 polysomy with that seen in cases with HER2 gene amplification and those with neither amplification or polysomy. We found that invasive breast carcinomas with unamplified chromosome 17 polysomy are associated with several adverse prognostic indicators such as a higher nuclear grade, mitotic activity, Nottingham score, histologic grade, tumor stage, and greater estrogen receptor negativity with a trend towards the amplified group, in contrast to patients with neither amplification or polysomy. Although most patients with unamplified 17 polysomy have a 2 + equivocal score on immunohistochemistry, a minority has a 3 + positive score. An increased adverse role for unamplified polysomy along with $3+$ protein expression in some patients supports the idea that these patients should be considered for therapy with trastuzumab and/or anthracyclines.
\end{abstract}

Modern Pathology (2009) 22, 1044-1048; doi:10.1038/modpathol.2009.61; published online 24 April 2009

Keywords: breast carcinoma; chromosome 17 polysomy; HER2

The role of human epidermal growth factor receptor 2 (HER2) oncogene was first reported in breast cancers in $1987 .^{1}$ The HER2 oncogene is a member of the human epidermal growth factor receptor family and is located on the long arm of chromosome 17 (17q12-21.32). ${ }^{2}$ The HER2 protein is a $185 \mathrm{kDa}$ growth factor receptor with tyrosine kinase activity and is expressed on the cell surface. ${ }^{3,4}$ The HER2 oncoprotein is overexpressed in about $20 \%$ of breast cancers. HER2 gene amplification is respon-

Correspondence: Dr U Krishnamurti, MD, PhD, Department of Pathology, Western Pennsylvania Hospital, 1104 West Tower, 4800 Friendship Avenue, Pittsburgh, PA-15224, USA.

E-mails: ukrishna@wpahs.org; ukrishna63@yahoo.com

Received 30 January 2009; revised 27 March 2009; accepted 29

March 2009; published online 24 April 2009 sible for protein overexpression in approximately $90 \%$ of breast carcinomas. ${ }^{5,6}$ Overexpression of the protein leads to increased cell proliferation. HER2 overexpression is an established adverse prognostic factor in breast cancer. HER2 overexpression in both node-positive and node-negative breast cancer is associated with a poor prognosis, and several studies have found a correlation between HER2 overexpression and a shorter disease-free period and shorter overall survival. ${ }^{7-9}$

The overexpressed protein is the therapeutic target for treatment with humanized monoclonal antibody, trastuzumab. ${ }^{10,11}$ Trastuzumab has been demonstrated to be effective in the treatment of breast carcinoma either as a single agent or in combination with traditional chemotherapy. ${ }^{12}$ HER2 overexpression is also a negative predictor for 
response to alkylating agents and a positive predictor for response to anthracyclines. However, a subset of breast cancers have chromosome 17 aneusomy, because of either 17 monosomy (a single copy of chromosome 17) or polysomy (increased copy numbers of chromosome 17). Polysomy for chromosome 17 may lead to increased HER2 gene dosage and these cases may or may not be associated with HER2 gene amplification. The incidence of chromosome 17 polysomy reported in the literature ranges from $5-50 \% .{ }^{13-16}$ Although there are several studies correlating polysomy/aneusomy of chromosome 17 with immunohistochemistry for HER2 amplification, there is a paucity of literature on the correlation of chromosome 17 aneusomy with important prognostic and predictive pathologic parameters in invasive breast carcinoma.

The aim of this study was to evaluate prognostic and predictive factors in invasive breast carcinoma in patients with unamplified chromosome 17 polysomy compared to patients with HER2 amplification and those with neither amplification nor polysomy.

\section{Materials and methods}

We evaluated cases of invasive breast carcinoma analyzed by fluorescence in situ hybridization (FISH) from $1 / 1 / 2005$ to $6 / 30 / 2007$. FISH was performed utilizing the federal drug administration approved Pathvysion HER2 DNA probe kit from Abbott/Molecular. The manufacturer's instructions were followed with no modifications. Sections were viewed using a fluorescence-equipped Zeiss Axioplan microscope. Polysomy was defined as the presence of $\geq 3.0$ CEP17 copies/cell and HER2 amplification was defined by a HER2/CEP17 copy ratio $>2.2$. Three groups consisting of Normal-no polysomy and no amplification, 36 cases (N), 17 polysomy without amplification, 44 cases $(\mathrm{P})$, and HER2 amplification without polysomy, 35 cases (A), were correlated with Nottingham score, tubule formation, nuclear grade, mitotic activity, histologic grade, lymph vascular invasion, lymph node status, tumor stage, estrogen receptor and progesterone receptor negativity. Statistical analysis was performed using the statistical software SAS version 9.2 and a Z-test of two proportions was performed.

\section{Results}

Of 365 cases analyzed by FISH in the laboratory, polysomy 17 was detected in 83 patients $(23 \%)$, of which 61 patients had unamplified polysomy $(17 \%)$.

The distribution of Nottingham score and the histological grade in the different groups studied are shown in Tables 1 and 2 . The most frequently occurring Nottingham score in group $\mathrm{N}$ was 6 compared with a score of 8 in $\mathrm{P}$ and scores of both 8 and 9 in A. For a score of 8 , the difference between
Table 1 Distribution of Nottingham score in N, P, and A groups

\begin{tabular}{lrrr}
\hline Score & $N(\%)$ & $P(\%)$ & $A(\%)$ \\
\hline 4 & 10 & 0 & 0 \\
5 & 15 & 9 & 0 \\
6 & 39 & 15 & 12 \\
7 & 14 & 25 & 20 \\
8 & 11 & 37 & 34 \\
9 & 11 & 14 & 34 \\
\hline
\end{tabular}

Table 2 Distribution of histologic grade in N, P, and A groups

\begin{tabular}{lrrr}
\hline Histologic grade & $N(\%)$ & $P(\%)$ & $A(\%)$ \\
\hline 1 & 25 & 10 & 0 \\
2 & 54 & 46 & 31 \\
3 & 21 & 44 & 69 \\
\hline
\end{tabular}

$\mathrm{N}$ and both $\mathrm{P}$ and $\mathrm{A}$ was significant $(P<0.01)$, whereas the difference between $\mathrm{P}$ and $\mathrm{A}$ was not significant. For a score of 9, group A had a significantly higher frequency compared with both $\mathrm{N}$ and $\mathrm{P}(P<0.05)$. Histological grade 2 was the most frequent in group $\mathrm{N}$, grade 3 most frequent in group A, whereas grades 2 and 3 were equally distributed in group P. Grade 3 was significantly higher in frequency in both $\mathrm{P}$ and A groups compared with $\mathrm{N}$ $(P<0.05)$. Furthermore, A had a greater frequency of cases with grade 3 compared with $\mathrm{P}(P=0.02)$. A tubule score of 3 was most frequent in all three groups and the differences were not significant (data not shown). Distribution of nuclear grade is shown in Table 3 and mitotic score in Table 4. Nuclear grade 2 was most frequent in group $\mathrm{N}$, compared with nuclear grade 3 in groups $\mathrm{P}$ and $\mathrm{A}(P<0.005)$. Although the frequency of nuclear grade 3 in group A was higher than that seen in group $\mathrm{P}$, the difference was not statistically significant. Mitotic score 1 was most frequent in group N. Mitotic score of 2 was significantly higher in both $\mathrm{A}$ and $\mathrm{P}$ compared with $\mathrm{N}(P<0.01)$. Frequency of mitotic score 3 was higher in group A compared with group $\mathrm{P}$, but the difference was not statistically significant.

Tumor stage 2 was seen in $18 \%$ of N, $31 \%$ of $\mathrm{P}$ and $30 \%$ of $\mathrm{A}$. The difference between the three groups was not statistically significant. Lymph vascular invasion was noted on hematoxylin and eosin sections in $17 \%$ of $\mathrm{N}, 19 \%$ of $\mathrm{P}$, and $34 \%$ of $\mathrm{A}$. Although lymph vascular invasion was higher in A compared with both $\mathrm{N}$ and $\mathrm{P}$, the difference was not statistically significant. Positive lymph nodes were detected in $38 \%, 42 \%$, and $45 \%$ of $\mathrm{N}, \mathrm{P}$, and $\mathrm{A}$ respectively, and the differences were not statistically significant.

The percentage of estrogen receptor and progesterone receptor negativity is given in Table 5 . Estrogen receptor negativity was seen more in $\mathrm{P}$ and A compared with $\mathrm{N}(P<0.05)$. Cases with HER2 amplification had a significantly greater frequency 
of estrogen receptor negativity than those with unamplified polysomy $(P=0.05)$. The difference in progesterone receptor negativity was not significant between the three groups.

Table 6 summarizes the key findings detailed in Tables 1-5.

About $13 \%$ of cases of unamplified polysomy 17 in our laboratory (eight cases) have $3+$ HER2 immunohistochemistry. Although the number of patients with $3+$ immunohistochemistry and unamplified polysomy 17 is too small to form conclusions, this group had a greater percentage of patients with more adverse prognostic factors. Of these eight cases, seven had histologic grade 3 , three had lymph vascular invasion, five had tumor stage 2 or higher, and two patients had subsequent local recurrences. One patient with $3+$ immunohistochemistry and unamplified polysomy 17 had lymph

Table 3 Distribution of nuclear grade in N, P, and A groups

\begin{tabular}{lrrr}
\hline Nuclear grade & $N(\%)$ & $P(\%)$ & $A(\%)$ \\
\hline 1 & 19 & 9 & 0 \\
2 & 55 & 30 & 26 \\
3 & 26 & 61 & 74
\end{tabular}

Table 4 Distribution of mitotic score in N, P, and A groups

\begin{tabular}{lrrr}
\hline Mitotic score & $N(\%)$ & $P(\%)$ & $A(\%)$ \\
\hline 1 & 64 & 20 & 17 \\
2 & 18 & 54 & 43 \\
3 & 18 & 26 & 40 \\
\hline
\end{tabular}

Table 5 ER and PR negativity N, P, and A groups

\begin{tabular}{lrrr}
\hline Hormone receptor negative & $N(\%)$ & $P(\%)$ & $A(\%)$ \\
\hline ER negative & 11 & 30 & 50 \\
PR negative & 24 & 35 & 34 \\
\hline
\end{tabular}

node and brain metastases at presentation. To the best of our knowledge, local recurrences or distant metastases were not seen in our patients with unamplified polysomy 17 who were $0-2+$ by immunohistochemistry.

\section{Discussion}

We have demonstrated that invasive breast carcinoma with unamplified chromosome 17 polysomy is associated with several adverse prognostic indicators such as a higher nuclear grade, mitotic activity, Nottingham score, histologic grade, tumor stage, and greater estrogen receptor negativity with a trend towards the amplified group, in contrast to patients with neither amplification nor polysomy. Nodal involvement showed no significant correlation in the groups. There is some heterogeneity for these adverse prognostic indicators in the group of patients with unamplified polysomy 17 . Differences in the level of polysomy and in the number of HER2 copies/cell thereof could contribute to this heterogeneity. Authors have reported higher HER2 copy numbers and greater frequency of discordance between immunohistochemistry and FISH for HER2 in cases with high polysomy than in cases with low polysomy. ${ }^{17-19}$

There are only a few other studies that have examined prognostic and/or predictive factors in chromosome 17 aneusomy or polysomy. Watters et $a{ }^{20}{ }^{20}$ found aneusomy 17 to be associated with grade 3 carcinoma $(P=0.008)$, estrogen receptor negativity $(P=0.0032)$ and a Nottingham prognostic index of greater than $5.4(P=0.039)$, but was not associated with survival by univariate analysis.

Tsukamoto et $a l^{16}$ found lymph node metastasis to be significantly correlated with polysomy of chromosomes 1,11, and 17. Progesterone receptor negativity was significantly higher in patients with polysomy of chromosomes 11 and 17 in their study $(P<0.05)$. Takehisa et $a 1^{14}$ also found a statistical correlation with a high histology grade in cases with polysomy 17. Lu et $a^{21}$ found polysomy 17 with or without amplification to be associated with high

Table 6 Summary of key findings in tables 1-5

\begin{tabular}{|c|c|c|c|c|c|}
\hline Prognostic and predictive factors & $N(\%)$ & $P(\%)$ & $A(\%)$ & $N$ vs $P$ & $P$ vs $A$ \\
\hline Nottingham score-8 & 11 & 37 & 34 & $P=0.008$ & - \\
\hline Nottingham score-9 & 11 & 14 & 34 & - & $P=0.033$ \\
\hline Nuclear grade-3 & 26 & 61 & 74 & $P=0.002$ & - \\
\hline Mitotic score-2 & 18 & 54 & 43 & $P=0.001$ & - \\
\hline Mitotic score-3 & 18 & 26 & 40 & - & - \\
\hline Histologic grade 3 & 20 & 44 & 69 & $P=0.02$ & $P=0.02$ \\
\hline T stage- 2 & 18 & 31 & 30 & - & - \\
\hline Lymph vascular invasion present & 17 & 19 & 34 & - & - \\
\hline Positive LN & 38 & 42 & 45 & - & - \\
\hline ER negativity & 11 & 30 & 50 & $P=0.04$ & $P=0.05$ \\
\hline PR negativity & 24 & 35 & 34 & - & - \\
\hline
\end{tabular}

$-=$ not significant 
nuclear atypia and with lymphatic metastases. Salido et $a l^{22}$ found that although nodal involvement was significantly associated with polysomy 17 $(P=0.046)$ and patients with polysomy 17 showed a non-statistical trend towards relapse $(P=0.181)$, there was no statistically significant correlation between histologic grade, estrogen receptor, progesterone receptor status and polysomy 17 . Torrisi et $a l .^{13}$ also found that unamplified polysomy was not associated with poor prognostic factors.

There could be a number of reasons for adverse behavior in patients with unamplified polysomy 17, such as increased levels of HER2 protein because of increased gene dosage. Although some authors have shown overexpression of HER2 mRNA both with or without HER2 amplification, ${ }^{23}$ majority of published literature indicates that polysomy 17 does not have an effect on HER2 mRNA content. ${ }^{17,24,25}$

It is well known that cancer tumorigenesis is a complex process. In addition to overexpression secondary to HER2 gene amplification, other molecular mechanisms can contribute to HER2 protein overexpression. Regulation of HER2 expression at the transcriptional level, alternative splicing with isoforms such as herstatin are some ways protein expression can be altered. ${ }^{26}$ There may be amplification of other potentially oncogenic genes and this may facilitate the generation of other genetic aberrations. $^{27}$ For example, topoisomerase II- $\alpha$ (TOP2A) is an enzyme that represents a molecular target for anthracyclines. In fact the relationship of HER2 to response to anthracyclines has been proposed as possibly being due to the close localization of HER2 and TOP2A on 17q. It has been a subject of debate whether these two genes behave separately or act together. ${ }^{28}$ In addition to alternate mechanisms at the nucleic acid level, recycling of the oncoprotein and altered protein degradation by changes in protein ubiquitination are other mechanisms that can result in HER2 protein overexpression. ${ }^{29}$ Magnifico et.al ${ }^{30}$ in their study suggest that HER2 overexpression in some HER2 $2+$ breast carcinomas is due to an accumulation of recycled oncoprotein on the cell surface induced by activation of protein kinase C- $\alpha$ Alternate mechanisms occurring at the protein level would explain how HER2 protein can be overexpressed without changes in HER2 mRNA levels. Therefore, increased adverse parameters in patients with unamplified polysomy 17 could be secondary to activation of other oncogenes that have not yet been identified or at the level of the protein itself by alterations in its half-life.

Although we may not fully understand the reasons for the presence of increased adverse parameters in patients with unamplified polysomy 17 , it is important to consider whether these patients should be treated differently. Currently patients with unamplified polysomy 17 are treated similar to patients with neither amplification or polysomy. Although most patients with unamplified polysomy
17 have a $2+$ equivocal expression of HER2 protein on immunohistochemistry, some patients have a $3+$ positive score for overexpression on immunohistochemistry (13.0\% in our laboratory, data not shown). Hofmann et $a l^{31}$ reported a subset of patients (2/4) with unamplified 17 polysomy and $3+$ HER2 immunohistochemistry expression responding to treatment with trastuzumab. The authors in that study concluded that chromosome 17 polysomy appeared to be a major cause of clinical responses to trastuzumab in FISH-negative cases and they propose that patients who are HER2-positive, but FISHnegative should be first retested by immunohistochemistry, and patients with positive results should be considered for trastuzumab therapy.

An increased adverse role for unamplified polysomy along with $3+$ protein overexpression supports the idea that these patients should be considered for therapy with trastuzumab and/or anthracyclines. However, definitive recommendations can be made only after randomized clinical trials testing the efficacy of trastuzumab therapy in patients with unamplified polysomy.

\section{Conflict of interest}

The authors declare no conflict of interest.

\section{References}

1 van de Vijver M, van de Bersselaar R, Devilee P, et al. Amplification of the neu (c-erbB-2) oncogene in human mammmary tumors is relatively frequent and is often accompanied by amplification of the linked cerbA oncogene. Mol Cell Biol 1987;7:2019-2023.

2 Popescu NC, King CR, Kraus MH. Localization of the human erbB-2 gene on normal and rearranged chromosomes 17 to bands q12-21.32. Genomics 1989;4:362-366.

3 Akiyama T, Sudo C, Ogawara H, et al. The product of the human c-erbB-2 gene: a 185-kilodalton glycoprotein with tyrosine kinase activity. Science 1986; 232:1644-1646.

4 Kokai Y, Cohen JA, Drebin JA, et al. Stage- and tissuespecific expression of the neu oncogene in rat development. Proc Natl Acad Sci USA 1987;84:8498-8501.

5 Slamon DJ, Clark GM, Wong SG, et al. Human breast cancer: correlation of relapse and survival with amplification of the HER-2/neu oncogene. Science 1987;235:177-182.

6 Slamon DJ, Godolphin W, Jones LA, et al. Studies of the HER-2/neu proto-oncogene in human breast and ovarian cancer. Science 1989;244:707-712.

7 Gusterson BA, Gelber RD, Goldhirsch A, et al. Prognostic importance of c-erbB-2 expression in breast cancer. International (Ludwig) Breast Cancer Study Group. J Clin Oncol 1992;10:1049-1056.

8 Press MF, Pike MC, Chazin VR, et al. Her-2/neu expression in node-negative breast cancer: direct tissue quantitation by computerized image analysis and association of overexpression with increased risk of recurrent disease. Cancer Res 1993;53:4960-4970. 
9 Andrulis IL, Bull SB, Blackstein ME, et al. neu/erbB-2 amplification identifies a poor-prognosis group of women with node-negative breast cancer. Toronto Breast Cancer Study Group. J Clin Oncol 1998;16: 1340-1349.

10 Baselga J, Norton L, Albanell J, et al. Recombinant humanized anti-HER2 antibody (Herceptin) enhances the antitumor activity of paclitaxel and doxorubicin against HER2/neu overexpressing human breast cancer xenografts. Cancer Res 1998;58:2825-2831.

11 Cobleigh MA, Vogel CL, Tripathy D, et al. Multinational study of the efficacy and safety of humanized anti-HER2 monoclonal antibody in women who have HER2-overexpressing metastatic breast cancer that has progressed after chemotherapy for metastatic disease. J Clin Oncol 1999;17:2639-2648.

12 Fornier M, Esteva FJ, Seidman AD. Trastuzumab in combination with chemotherapy for the treatment of metastatic breast cancer. Semin Oncol 2000;27(6 Suppl 11):38-45; discussion 92-100.

13 Torrisi R, Rotmensz N, Bagnardi V, et al. HER2 status in early breast cancer: relevance of cell staining patterns, gene amplification and polysomy 17. Eur J Cancer 2007;43:2339-2344.

14 Takehisa M, Sasa M, Bando Y, et al. Chromosomal aneusomy (chr 1,11,17) detected by fluorescence in situ hybridization may be a prognostic factor in breast cancer. Anticancer Res 2007;27:1073-1078.

15 Hyun CL, Lee HE, Kim KS, et al. The effect of chromosome 17 polysomy on HER-2/neu status in breast cancer. J Clin Pathol 2008;61:317-321.

16 Tsukamoto F, Miyoshi Y, Egawa C, et al. Clinicopathologic analysis of breast carcinoma with chromosomal aneusomy detected by fluorescence in situ hybridization. Cancer 2001;93:165-170.

17 Dal Lago L, Durbecq V, Desmedt C, et al. Correction for chromosome-17 is critical for the determination of true Her-2/neu gene amplification status in breast cancer. Mol Cancer Ther 2006;5:2572-2579.

18 Lal P, Salazar PA, Ladanyi M, et al. Impact of polysomy 17 on HER-2/neu immunohistochemistry in breast carcinomas without HER-2/neu gene amplification. J Mol Diagn 2003;5:155-159.

19 Ma Y, Lespagnard L, Durbecq V, et al. Polysomy 17 in HER-2/neu status elaboration in breast cancer: effect on daily practice. Clin Cancer Res 2005;11:4393-4399.

20 Watters AD, Going JJ, Cooke TG, et al. Chromosome 17 aneusomy is associated with poor prognostic factors in invasive breast carcinoma. Breast Cancer Res Treat 2003;77:109-114.
$21 \mathrm{Lu}$ YL, Zhong M, Liu L, et al. [Clinicopathologic significance of chromosome 17 polysomy in breast cancer]. Zhonghua Bing Li Xue Za Zhi 2008;37: 88-91.

22 Salido M, Tusquets I, Corominas JM, et al. Polysomy of chromosome 17 in breast cancer tumors showing an overexpression of ERBB2: a study of 175 cases using fluorescence in situ hybridization and immunohistochemistry. Breast Cancer Res 2005;7:R267-R273.

23 Kraus MH, Popescu NC, Amsbaugh SC, et al. Overexpression of the EGF receptor-related protooncogene erbB-2 in human mammary tumor cell lines by different molecular mechanisms. EMBO J 1987; 6:605-610.

24 Downs-Kelly E, Yoder BJ, Stoler M, et al. The influence of polysomy 17 on HER2 gene and protein expression in adenocarcinoma of the breast: a fluorescent in situ hybridization, immunohistochemical, and isotopic mRNA in situ hybridization study. Am J Surg Pathol 2005;29:1221-1227.

25 Vanden Bempt I, Van Loo P, Drijkoningen M, et al. Polysomy 17 in breast cancer: clinicopathologic significance and impact on HER-2 testing. J Clin Oncol 2008;26:4869-4874.

26 Doherty JK, Bond C, Jardim A, et al. The HER-2/neu receptor tyrosine kinase gene encodes a secreted autoinhibitor. Proc Natl Acad Sci USA 1999; 96:10869-10874.

27 Vanden Bempt I, Drijkoningen M, De Wolf-Peeters C. The complexity of genotypic alterations underlying HER2-positive breast cancer: an explanation for its clinical heterogeneity. Curr Opin Oncol 2007;19: $552-557$.

28 Beser AR, Tuzlali S, Guzey D, et al. HER-2, TOP2A and chromosome 17 alterations in breast cancer. Pathol Oncol Res 2007;13:180-185.

29 Lipkowitz S. The role of the ubiquitination-proteasome pathway in breast cancer: ubiquitin mediated degradation of growth factor receptors in the pathogenesis and treatment of cancer. Breast Cancer Res 2003;5:8-15.

30 Magnifico A, Albano L, Campaner S, et al. Protein kinase Calpha determines HER2 fate in breast carcinoma cells with HER2 protein overexpression without gene amplification. Cancer Res 2007;67: 5308-5317.

31 Hofmann M, Stoss O, Gaiser T, et al. Central HER2 IHC and FISH analysis in a trastuzumab (Herceptin) phase II monotherapy study: assessment of test sensitivity and impact of chromosome 17 polysomy. J Clin Pathol 2008;61:89-94. 